\title{
DO POSITIVISMO À SOCIOLOGIA DO BEM JURÍDICO PENAL: UMA ATUALIZAÇÃ̃O CENTRADA NA CONSTRUÇÃ̃ DA ORDEM PÚBLICA FUNDADA EM UMA DIMENSÃO CIDADÃ ATIVA.
}

\author{
Claudio Alberto Gabriel Guimarães* \\ Davi Uruçu Rego**
}

RESUMO: A busca por uma melhor configuração teórica do que seja um bem jurídico penal e, em razão de tal qualidade, seja merecedor de proteção através do sistema formal de controle social e, por via de consequência, pelo Direito Penal, é o escopo do presente texto. Assim, a partir do pressuposto de que a função protetora de bens jurídicos penais em conexão com a cidadania ativa permite delimitar o conceito de bem jurídico penal afinado à realidade social contemporânea, ultrapassar-se-á, pois, a formulação acrítica do positivismo em prol de uma perspectiva sociológica.

PALAVRAS-CHAVE: Controle Social. Sistema Penal. Bem Jurídico Penal. Democracia Deliberativa. Cidadania Ativa.

\section{FROM POSITIVISM TO THE SOCIOLOGY OF CRIMINAL LEGAL GOOD: AN UPDATE CENTERED ON THE CONSTRUCTION OF PUBLIC ORDER FOUNDED ON AN ACTIVE CITIZEN DIMENSION.}

\begin{abstract}
The search for a better theoretical configuration of what is a criminal legal good and, due to such quality, deserves protection through the formal system of social control and, consequently, by Criminal Law, is the scope of this text. Thus, based on the assumption that the protective function of criminal legal assets in connection with active citizenship allows for delimiting the concept of criminal legal property in tune with contemporary social reality, the uncritical formulation of positivism in favor of from a sociological perspective.
\end{abstract}

KEY WORDS: Social Control. Penal System. Criminal Legal Goods. Deliberative Democracy. Active Citizenship.

\footnotetext{
* Promotor de Justiça do Estado do Maranhão. Especialista em Direito, Estado e Sociedade pela Universidade Federal de Santa Catarina. Especialista em Docência Superior pela Universidade CEUMA - UNICEUMA. Mestre em Direito Público pela Universidade Federal de Pernambuco - UFPE. Mestre em Gestão de Segurança pelo Instituto Superior de Ciências Policiais e Segurança Pública - ISCPSP, Doutor em Direito Público pela Universidade Federal de Pernambuco - UFPE, com área de concentração em Direito Penal. Doutor em Direito pela Universidade Federal de Santa Catarina - UFSC, com área de concentração em Criminologia. Pós-Doutorando pela Universidade de Lisboa - FDUL, com área de estudos em Teoria da Pena. Professor Pesquisador do CNPq e da Universidade CEUMA - UNICEUMA. Coordenador do Núcleo de Pesquisas em Violência e Cidadania - NEVIC da Universidade CEUMA - UNICEUMA. Professor da Escola Superior do Ministério Público do Estado do Maranhão, Professor Adjunto da Universidade Federal do Maranhão dos cursos de graduação e do Programa de Mestrado em Direito e Instituições do Sistema de Justiça. calguimaraes@ yahoo.com.br

** Bacharel em Direito pela universidade CEUMA - UNICEUMA. Assessor de Procurador de Justiça no Ministério Público do Estado do Maranhão. Mestrando em Direito e Instituições do Sistema de Justiça pela Universidade Federal do Maranhão (UFMA).davi@mpma.br
} 


\section{INTRODUÇÃO.}

O bem jurídico penal é um objeto de estudo que perpassa grande parte do desenvolvimento teórico do Direito Penal, avultando, ainda hoje, como de suma importância para o estabelecimento de limites e, assim, configuração de fundamentos que legitimem a aplicação do direito punitivo.

Partindo-se do pressuposto da ampla e, consequentemente, inadequada utilização do argumento do bem jurídico penal - com escolhas cada vez mais pautadas em necessidades políticas que na necessária juridicidade que estes deveriam refletir - para justificar a utilização do controle social formal e, portanto, do Direito Penal para a proteção dos mesmos, entende-se que muito vagas, ilimitadas e, por não poucas vezes, casuísticas são as diretrizes para escolha destes bens.

Logo, necessário que se investigue quais os critérios que podem, de maneira efetiva e segura, em dias de crescente demanda por uma maior proteção penal em sociedades alarmadas pela crescente violência - quer real, quer virtual -, em suas mais variadas formas, ser levados em consideração em busca desta imprescindível delimitação.

Desta feita, pensa-se ser pertinente, mais do que indagar sobre quais os bens jurídicos que devem ser elevados à categoria de defensáveis pelo Direito Penal, questionar sobre quais os critérios que devem ser levados em consideração, de forma concreta e não apriorística, para que determinado bem jurídico possa alcançar o status de bem jurídico penal.

Afigura-se ser esse, senão o único, mas o mais promissor caminho para combater diversas distorções, hoje imanentes ao Direito Penal, em razão de uma inflação legislativa que traz a reboque, de há muito, os adjetivos de simbólico, estigmatizante, seletivo, desigual e desnecessário, dentre tantos outros argumentos que questionam a legitimidade do Direito de Punir do Estado.

Assim, o presente trabalho tem por objetivo favorecer a atualização da perspectiva conceitual de que se utiliza, amplamente, a Ciência Penal ${ }^{1}$ para definir o que é o bem jurídico penal.

O caminho metodológico percorrido passa pela abordagem indutiva - ao nosso sentir a mais adequada para elaboração de pesquisas no campo das Ciências Sociais -, posto que em

\footnotetext{
${ }^{1}$ Adota-se aqui a posição de Liszt (2003), hodiernamente endossado por outros autores, como Palma (2016), que defende o ponto de vista, segundo o qual, a Dogmática Penal, a Criminologia e a Política Criminal devem compor o arcabouço teórico das Ciências Criminais.
} 
constante busca para ampliar o que até então estabelecido cientificamente sobre o objeto pesquisado.

Não sendo objetivo do presente texto discutir questões metodológicas, entende-se que pela via da indução adentra-se no campo teórico-interpretativo da realidade para, através daquilo que é sobejamente conhecido - entretanto, imune a consensos - se chegar a ilações até então não realizadas; nesse caminhar, respeitando-se as exigências epistemológicas do fazer ciência, mas no âmbito de perspectivas metodológicas abertas e críticas ${ }^{2}$, pela via da argumentação intenta-se ampliar o que está estabelecido, passando-se para o desconhecido, do particular para o geral, com o objetivo último de se elaborar uma forma de conhecimento com o necessário rigor científico.

Através de um procedimento jurídico-propositivo, entende-se que a técnica de pesquisa mais adequada para desenvolver e operacionalizar tal abordagem metodológica é o da pesquisa qualitativa de cunho teórico, haja vista que será aprofundada a pesquisa pela via exclusivamente bibliográfica; pela análise eminentemente conceitual centrada em um único tema, intenta-se rever teorias e conceitos, com a incessante busca do novo, o que não impede, por certo, o necessário estabelecimento de um diálogo interdisciplinar, com contribuições da Ciência Política, da História e da Filosofia ${ }^{3}$.

Para tanto, inicia-se o texto apresentando o locus em que o corpo social desenvolve suas necessidades através da manutenção da ficção jurídica do pacto social, enquanto imprescindível para a ação mantenedora da ordem pública.

E, nesse desiderato, aprofunda-se o estudo do controle social institucionalizado, sob a ótica do sistema penal, como mecanismo fiel aos planos estatuídos pelo Estado, cujo binômio liberdade-segurança, amiúde, está na centralidade dos debates realizados.

Em seguida, no segundo tópico, estimula-se a reflexão sobre a função protetora de bens jurídicos penais, assim como, discorre-se sobre a cidadania ativa, exercitada no âmbito da democracia deliberativa, como forma de subsidiar a edição de um conceito de bem jurídico afinado à realidade social contemporânea, ultrapassando-se, pois, a formulação acrítica do positivismo em prol de uma perspectiva sociológica.

\footnotetext{
${ }^{2}$ Assim, Bachelard (1999).

${ }^{3}$ Nessa perspectiva, cfr. Gustin e Dias (2015) e Minayo (2018).
} 
Esse o caminho escolhido para, longe de dar termos finais à questão, suscitar o aprofundamento do debate acerca de uma temática que reputa-se fundamental para o evoluir dos fundamentos que justificam e legitimam o direito punitivo.

\section{O CORPO SOCIAL E A ORDEM PÚBLICA ${ }^{4}$ : um espaço para o exercício de direitos.}

Vista do alto a sociedade é uma ilha de tranquilidade. Caseira e agradável à maioria daqueles que a sobrevoam é minuciosa em dissuadir o mar de turbulência e hostilidade que contém.

Sua racionalidade seduz pelos argumentos organizacionais e coletivos da metáfora de um só corpo voltado para as realizações comuns; e, repetidas vezes, o ecoar desse cântico impede o exame de suas minúcias e dos valores da vida que estão em jogo.

Sutil e doce, esse cântico ressoa como um mantra, fazendo transparecer que o contrato social é o ato pelo qual um povo acaba por se constituir, de forma real, como um povo, haja vista que, no Estado do contrato, a soberania do povo como corpo coincide com a vontade de um ser coletivo que só pode ser representado por sí mesmo ${ }^{5}$.

E, fruto desse mantra, exsurge no pacto social a vontade geral própria desse "corpo moral e coletivo", cuja unidade, indivisibilidade e perfeita retidão são características sine qua non.

Contudo - e sem desprezar este legado romântico deixado pelo construtivismo racionalista do Iluminismo -, talvez deva-se conferir razão à visão segundo a qual a sociedade é aquele corpo em cuja proteção abriga-se o horror de nossa própria transitoriedade ${ }^{6}$.

E se diz talvez porque acredita-se necessário fazer a devida atualização conceitual para tornar perceptível que a sociedade contemporânea - "viveiro da segurança" - é insistentemente volátil, sendo, portanto, fundamental compreender que a metáfora do corpo social - enquanto abrigo único $^{7}$ - apresenta-se aveludada por dentro e áspera e espinhosa por fora $^{8}$.

\footnotetext{
${ }^{4}$ Dentre as definições atribuídas à ordem pública, Clemente (2015, p. 31) a compreende como um conjunto de requisitos extrajurídicos, ou mesmo pré-jurídicos - mas não alheios ao jurídico -, imprescindíveis ao bom funcionamento das instituições do Estado e da sociedade civil e garantidora da efetivação dos direitos da pessoa, devendo, inclusive, na percepção de Guimarães (2018, p. 42), ser constituída como referencial do controle social formal e informal, cuja característica mais marcante seja a evolução do campo meramente proibitivo para alcançar um patamar positivo, cuja principal esfera de atuação esteja calcada na busca inegociável do bem comum e na proteção dos bens jurídicos mais caros aos cidadãos enquanto corpo comunitário e enquanto indivíduos.

${ }_{5}^{5}$ Esse o pensamento de Rousseau (2013, p. 359 e ss.), um dos mais reconhecidos contratualistas. Acerca da percepção de que a "soberania do povo" se confunde com a "soberania nacional", Cfr. Sieyès (1982).

${ }^{6}$ Assim, Durkheim (1972, p. 72 e ss.)

${ }^{7}$ Uma opinião em sentido contrário pode ser vislumbrada em Thoreau (2017).
} 
Esses limites traçam o horizonte e as linhas divisórias existentes entre o domínio da confiança e do cuidado amoroso ofertados àqueles que conferem coesão ao corpo social e o da suspeição e perpétua vigilância àqueles que realizam o movimento em sentido contrário.

Assim, da dimensão individual à dimensão comunitária ${ }^{9}$, o corpo social realiza um movimento sonâmbulo em que as ações e interações ocorrem por mimetismo, irrefletidamente. E, nesse contexto, aquilo que sobressalta aos olhos mais atentos é o fato de que, na contemporaneidade, inexiste clareza filosófica nas justificações concedidas e nos limites impostos a todos.

Apenas deixa-se navegar. Multiplica-se, portanto, a vasta ordem de desejos sociais em uma infinidade de correntes propositivas e ondas domadoras, cujo horizonte, invariavelmente, enreda o binômio liberdade-segurança.

Não obstante, ressoa uma antinomia latente entre ambas, porque a constante oposição com que são apresentadas ao corpo social, amiúde, faz acreditar que não se pode querer mais de uma sem renunciar a um tanto, talvez grande parte, da outra.

No atual momento de complexificação das sociedades ${ }^{10}$, esse exercício de guerra entre liberdade e segurança se exaspera e a fenda existente entre elas é potencializada por uma busca desenfreada por mecanismos de proteção - sejam eles de efeito mediato ou imediato o importante é sentir-se seguro!

Veja-se, assim, que a linha de trincheira por consecução de segurança assume uma preocupação obsessiva e febril ante a multiplicidade e potencialidade dos riscos que a sociedade atual cria ${ }^{11}$.

\footnotetext{
${ }^{8}$ Assim Bauman (2001, p. 208 e ss.). Nessa perspectiva e em termos bastante pedagógicos, delineia-se que, se por um lado, o liberalismo clássico traz a conquista da individualidade, por outro, não reconhece a comunidade. E, ao revés, o comunitarismo vem justamente trazer o senso de pertencimento a uma comunidade, porém excluindo quem nela não se encaixa. Para maior aprofundamento sobre as características do Liberalismo e do Comunitarismo, Cfr. Sandel (1996), Rawls (2000) e Walzer (2003).

${ }^{9}$ Sobre a ausência ou desintegração entre o sistema de valores e o sistema das normas sociais, Cfr. Durkheim (1972) e Merton (1964).

${ }_{10}$ Para um maior aprofundamento acerca da sociedade do risco, Cfr. Beck (1998), Buergo (2001) e Cavalcanti (2005).

${ }^{11}$ Ao discorrer sobre o conceito de Sociedade do Risco - ou de Risco, para alguns autores - Fernandes (2001, p. 46) destaca ser merecedor de atenção o lado obscuro do desenfreado desenvolvimento da técnica, que traz a reboque, invariavelmente, a falácia do seu sistema de cálculo de riscos, que originou, origina, e virá certamente a originar, consequências negativas, dentre as quais aquelas que se direcionam para por em perigo a própria continuação da vida no planeta. Em igual sentido, Guimarães e Rego (2008, p. 184) contribuem com a temática advertindo que a expressão sociedade do risco representa uma reviravolta da ideia de risco tradicionalmente moldado sob os alentos de total controle da Modernidade, vez que, os riscos que se podiam calcular na esteira daquele contexto, tornaram-se incalculáveis e imprevisíveis na sociedade dos riscos contemporâneos.
} 
Por essa via, transpassa-se da coexistência em nome da liberdade para a coexistência em nome da segurança e, isso se introduz, no contexto contemporâneo, de forma bastante perceptível, em que parte da população não convive diretamente com a violência, mas sim com a sua intensa e exaustiva divulgação nos meios de comunicação, ampliando os seus efeitos e criando um significativo aumento da consciência dos riscos e das violências que são ameaçadoras.

Todo esse contexto leva, de forma avassaladora, à indeterminação do futuro, que por sua vez, conduz à incerteza, caracterizada, principalmente, por se constituir como um perigoso fator de insegurança que conta, na esfera política, com a emocionalização e a moralização do discurso público ${ }^{12}$.

A violência, concretude da insegurança, então, passa a apresentar uma natureza subjetiva, passa a ser também um sentimento. E o sentimento de estar exposto, fragilizado, expressa uma subjetividade que é resultado da violência real, mesmo quando esta insegurança objetivamente não existe. Vive-se sob a sensação subjetiva do medo ${ }^{13}$ ! E, desta forma, o indivíduo passa a se sentir mais exposto aos perigos do que efetivamente está sob o risco de sofrer alguma violência ${ }^{14}$.

À radiografia do que expendido intersecciona-se ao controle social no afã de promover estabilidade a um corpo social cada vez mais dinâmico e antagônico em seus interesses e expectativas, cujo âmbito de resolutividade enreda dois caminhos ${ }^{15}$.

O primeiro realizado, de forma difusa, pela moralidade coletiva defendida pelo próprio corpo social e o segundo efetivado institucionalmente pelo Estado ${ }^{16}$.

\footnotetext{
${ }^{12}$ Indubitavelmente a mídia exerce inúmeras funções dentro do corpo social e, por óbvio, são bem mais complexas e sutis em seus desideratos que a mera função comunicativa. Nessa linha de pensamento, cfr. Silva (2004, p. 89 e ss.). Cfr., também, Batista (2002, p. 271), que, de forma perspicaz, observa que, para além da função comunicativa, a incerteza, a insegurança e o medo do outro que está ao derredor são sementes plantadas pelos meios de comunicação social e pelos titulares de cargos políticos, em função de interesses escusos que alavancam uma série de crenças e encobrem um silêncio sorridente sobre as informações que as desmintam. Para maior aprofundamento no tema, Cfr. Fernandes (2001) e Guimarães (2010).

${ }^{13}$ Para que a abordagem acerca da subjetivação do medo seja a mais adequada possível é preciso não olvidar que, além de artificiosamente arquitetada, esta sofre influxos diferenciados à compreensão e enfrentamento dos fenômenos desviantes causadores de temor social. Assim, a criminologia, enquanto ciência obstinada em compreender as causas ensejadoras da conduta delitiva, pode ofertar soluções distintas para a contenção de cada tipo de delinquente. Desta forma, segundo observa Garland (2002, p. 86), a criminologia oficial - cada vez mais dualista, polarizada e ambivalente - pode ser dividida em "criminologia de si" e "criminologia do outro". Assim, enquanto a primeira é invocada para trivializar o crime, moderar os medos desproporcionais e promover a ação preventiva, a segunda tende a demonizar o criminoso, estimulando os medos e as hostilidades populares defendendo intransigentemente a ideia, segundo a qual, o Estado deve punir mais.

${ }_{14}$ Assim, Dornelles (2002, p. 123 e ss.). Acerca das tendências mundiais do poder punitivo, Cfr. Zaffaroni (2007).

${ }^{15}$ Sobre a existência de controle em todas as sociedades organizadas, Cfr. Foucault (2003) e Garland (1999).
} 
Isso significa, em todo caso, que diante de qualquer situação conflituosa a solução pela via institucionalizada pelo Estado é somente uma das possíveis ${ }^{17}$.

Ocorre que, primordialmente, a via eleita é a institucionalizada através do sistema penal, o que, de fato, conduz a um inquestionável efeito negativo que consiste na exclusão das outras soluções possíveis.

Nesse caminhar, tão certo quanto o fato de que o sistema penal é parte do controle social - que resulta institucionalizado em forma punitiva e com discurso punitivo -, é o fato de que o direito penal ocupa somente um lugar limitado dentro deste sistema, sendo indispensável manter a racionalidade acerca do dimensionamento de seu campo de controle, a fim de que enganos onipotentes não produzam efeitos paradoxais ${ }^{18}$.

Requer-se, pois, criar um espaço de ordem pública em que o exercício de direitos não ceda às expectativas criadas pelo direito penal, enquanto fonte resolutiva de problemas políticos e sociais não equacionados por outras esferas de controle social ou mesmo ante a própria ausência de políticas destinadas a garantir prestações públicas essenciais à população.

Desta maneira, o problema que encerra este tópico perpassa pela forma a ser alcançada para solucionar estas exigências e, igualmente, lograr materialidade e concreção republicanas e

\footnotetext{
${ }^{16}$ Acerca da diferenciação entre o controle social formal e o controle social informal, Guimarães (2013) pondera que controle social informal é subliminar e ocorre de cidadão para cidadão, sendo pautado na história de cada povo, nos seus costumes e tradições, sem a interferência cogente do Estado. Assim realiza-se pela família, pela comunidade, pela religião, pela escola, pelas empresas, dentre outras instituições não necessariamente pertencentes ou ligadas a organismos oficiais. De outro lado, o controle social formal é exercido, ou deveria ser, exclusivamente pelo Estado, pelas mãos das instituições a quem preliminarmente é atribuída tal competência por força de lei. Assim sendo, é por necessidade de tal tipo de interferência no âmbito do controle social que surge o Direito Penal.

${ }_{17}$ Ainda sobre a temática do controle social informal, Viana (2002, p. 171-172) apregoa que este pode constituir excelente barreira à prevenção do comportamento desviante, seja porque atua, em regra, de modo preventivo, seja porque é capaz de impactar sobre a estruturação do controle interno do indivíduo, daí ser extraordinário o papel que a família, a escola e a educação, por exemplo, podem desempenhar no controle da criminalidade. Entretanto, o autor referenciado adverte que o controle formal sem o informal teria, quando muito, um efeito medíocre; e o controle informal sem as instâncias formais poderia tornar-se estéril, razão pela qual aduz ser possível falar em justaposição dos controles, afinal - ao menos no plano das hipóteses - o controle social formal somente entrará em ação quando $o$ informal falhar.

${ }^{18}$ Se é certo que há justaposição entre o controle social informal e o controle social formal - e, igualmente, que há uma relação de subsidiariedade entre este controle social e aquele -, não menos certo é o fato de que, em conformidade com Muñoz Conde (2012, p. 25-26, tradução livre), dentro do controle social a norma penal e todo o sistema jurídico-penal ocupam apenas um lugar secundário, puramente confirmador e assegurador de outras instancias muito mais sutis e eficazes. Desta feita, para o autor citado, a norma penal não cria novos valores, tampouco constitui um sistema autônomo de motivação do comportamento humano em sociedade. De forma que, entende ser inimaginável um direito penal completamente desconectado das demais instâncias de controle social, razão pela qual afirma que o direito penal não é mais que a parte visível - a mais tétrica e terrível, quiçá - do iceberg que representa os diversos mecanismos de controle do indivíduo na sociedade - conquanto não seja o único, nem o mais importante.
} 
democráticas indispensáveis na tarefa prática de aplicação do direito penal nesse espaço de ordem pública.

\section{EVOLUÇÃO CONCEITUAL: DO POSITIVISMO À SOCIOLOGIA DO BEM JURÍDICO PENAL ${ }^{19}$.}

Exposto o problema, é indubitável que a solução pretendida requer respostas tenazes e lógicas que sejam suficientemente dotadas de razoabilidade para alcançar a resolução do questionamento realizado.

Assim, não olvidando que a formulação elaborada se desdobra em duas partes ${ }^{20}$, iniciase o esforço para realizar esse desígnio de criar um espaço de ordem pública para o exercício de direitos a partir da análise do bem jurídico penal - aliás, do caminho percorrido até se chegar a essa categoria assaz importante para a dogmática penal e, sobretudo, para as inúmeras formas de agir desencadeadas no seio do corpo social.

Todavia, e advertidamente, é preciso ter consciência de que há múltiplas interações existentes entre as elaborações filosóficas justificantes, as estruturas de poder fincadas nas sociedades e as realidades sociais individualizáveis e temporalmente delimitadas ${ }^{21}$.

$\mathrm{E}$, nesse aspecto, esse conjunto de forças, quase nunca distribuídas igualitariamente, “elege" o (s) caminho (s) que o corpo deve seguir, suportar e amoldar-se, a fim de manter a ficção jurídica entabulada pelo contrato social.

Parte-se, pois, do conceito material de crime ${ }^{22}$ para descrever, com certa historicidade ${ }^{23}$, as balizas da estrada que conduziram à ideia contemporânea de bem jurídico, tão propalada e, ao mesmo tempo, carente de nascedouro ${ }^{24}$.

\footnotetext{
${ }^{19}$ Sobre o assunto, cfr. Prado (1996, p.32 e ss.), que faz detalhada análise sobre os posicionamentos de Knut Amelung, Winfried Hassemer e Jürgen Habermas, abordando temáticas como a relação entre a danosidade social e a constituição do bem jurídico, assim como, sobre a percepção do legislador do que seja necessário para estabelecer as condições de uma vida saudável da comunidade jurídica.

${ }^{20}$ A primeira referente à função protetora de bens jurídicos penais e a outra acerca da construção da perspectiva sociológica do bem jurídico a partir da dimensão cidadã da pessoa enquanto sujeito ativo transformador da realidade que se lhe insere.

${ }^{21}$ Para maior aprofundamento, Cfr. Zaffaroni (2007, p. 54-77), para quem é absolutamente certo que a naturalização do poder punitivo, por toda sua violenta história, o consolidou e, continua consolidando, como um acontecimento ahistórico, prescindindo-se, pois, de sua construção política oriunda do medievo ocidental colonial e posta como modelo planetário de verticalização e controle social.

${ }^{22} \mathrm{Na}$ abordagem em curso, após uma breve digressão acerca das perspectivas positivistas, é importante referenciar que, para o escólio doutrinário de Gomes (2007, p. 412), o conceito material de crime - que conduz ao encontro da teoria sociológica elaborada por Habermas - é aquele elaborado por Von Liszt (positivismo naturalista), firmado na percepção de que a ordem jurídica não cria o interesse, ele é criado pela vida; mas a proteção do Direito eleva o interesse vital à categoria de bem jurídico, sendo que os interesses vitais resultam das relações da vida entre os mesmos indivíduos ou entre os particulares e a sociedade organizada em Estado e vice-versa.
} 
Assim sendo, veja-se que, inicialmente, à pergunta sobre o que seja materialmente o crime assume uma perspectiva positivista-legalista - cujo teor compreende tudo e só aquilo que o legislador considerar como tal - para, em seguida, ceder lugar à perspectiva positivistasociológica, na qual o importante era divisar, através da multiplicidade das manifestações legais de crimes, aquilo que em termos de objetividade e universalidade pudesse - à luz da realidade social - ser como tal considerado, algo que existisse na sociedade humana independentemente de uma época ou concepção particular ${ }^{25}$

Conquanto verdadeiras em sua essência e louváveis em seus propósitos, as concepções referidas, dada a imprecisão que lhes embebe, revelaram baixíssima capacidade de rendimento na tarefa de determinar o conceito material de crime.

Não obstante, é imprescindível ressaltar o mérito conferido à perspectiva positivasociológica; que, pela primeira vez, e de forma ordenada e sistemática, procurou estabelecer um conceito pré-legal de crime.

Ao seu tempo, em nova guinada de perspectiva, o processo evolutivo correspondente à passagem do Estado de Direito formal ao Estado de Direito material desembocou na introdução no conceito material de crime de um ponto de vista moral (ético) -social que levava a ver em sua essência a violação de deveres ético-sociais elementares ou fundamentais.

Ocorre que não é função do direito penal tutelar a virtude ou a moral, quer se trate da moral imposta pelo Estado, da moral dominante, ou da moral de qualquer grupo social.

Desta feita, a configuração de um conceito material de crime por intermédio de uma perspectiva moral cria um campo de inadequação entre si e o pluralismo ético-social inerente às sociedades.

Nesse movimento dialético, a síntese dessas contradições dá origem a uma perspectiva qualificada de teleológico-funcional e racional.

\footnotetext{
${ }^{23}$ Acerca da evolução histórica da ideia de objeto jurídico do delito, Cfr. Prado (1995, p. 21-35).

${ }^{24} \mathrm{O}$ conceito de bem jurídico é um daqueles cuja origem é tão difícil de se precisar quanto o seu alcance. Não obstante isso, a doutrina majoritária atribui a Birnbaum o mérito de tê-lo introduzido no âmbito jurídico penal. E, a partir dessa constatação, Prado (1996, p. 25) pontua que o referido conceito foi introduzido no contexto jurídicopenal em substituição ao direito subjetivo, observando ser decisivo para a tutela penal a existência de um bem radicado diretamente no mundo do ser ou da realidade (objeto material), importante para a pessoa ou a coletividade e que pudesse ser lesionado pela ação delitiva. Desta feita, Gomes (2007, p. 411), complementando o sobredito, assevera que, embora Birnbaum não tenha falado diretamente em bem jurídico, indiscutivelmente foi o primeiro autor a contrapor a ideia da doutrina iluminista que via na danosidade social e na violação de direitos subjetivos os fundamentos da punição estatal.

${ }^{25}$ Para maior aprofundamento acerca da perspectiva positiva-sociológica, Cfr. Garofalo (1997) e Dias (2007).
} 
Destarte, será teleológico-funcional quando reconhece definitivamente que o conceito material de crime não podia ser deduzido das ideias vigentes em qualquer ordem extra-jurídica e extra-penal, mas, ao revés, deveria ser encontrado no horizonte da própria função que ao direito penal se adscrevesse no sistema jurídico-social. De outro lado, deveria ser racional ao compreender que o conceito material de crime resultaria da função atribuída ao direito penal de tutela subsidiária de bens jurídicos dotados de dignidade penal.

Chegando a este ponto, o esforço que agora deve ser posto em curso redunda, justamente, em indagar acerca da linha limítrofe que insere ou retira da categoria de bem jurídico o qualificativo da dignidade penal.

E, na oportunidade, é importante que se diga que a intenção se distancia do objetivo de exaurir as conceituações existentes de bens jurídicos e se aproxima da necessidade em conferir notoriedade ao objeto de estudo ${ }^{26}$.

Sob esse prisma, a primeira conceituação que se expõe parte da premissa do mínimo ético e assenta no fato de que o bem jurídico é um valor ético social possuidor de sentido positivo, ou seja, um bem vital da comunidade ou do indivíduo que, por sua significação social, é protegido juridicamente.

Noutro giro, consignou-se que a norma não cria o bem jurídico, mas sim o encontra porque o fim do direito não é outro que o de proteger os interesses do homem, não podendo de modo algum ser criação ou elaboração jurídica, mas se impõe a ela. Assim, o bem jurídico vem a ser, portanto, uma criação da experiência e como tal é um interesse vital do indivíduo ou da comunidade ${ }^{27}$.

Para além, diz-se que os bens jurídicos podem ser definidos como circunstâncias reais dadas ou finalidades necessárias pra uma vida segura e livre, que garanta a todos os direitos humanos e civis de cada um na sociedade ou para o funcionamento de um sistema estatal que se baseia nestes objetivos ${ }^{28}$.

Alargando um pouco mais a percepção, bem jurídico pode ser definido como a expressão de um interesse, da pessoa ou da comunidade, na manutenção ou integridade de um certo estado, objeto ou bem em si mesmo socialmente relevante e por isso juridicamente reconhecido como valioso.

\footnotetext{
26 Acerca da evolução histórica do conceito de bem jurídico, Cfr. Kist (2003, p. 147-154). Para maior aprofundamento acerca dos conceitos de bem jurídico, Cfr. Prado (1996, p. 35-40). E, sobre uma opinião crítica destinada ao referido conceito, Cfr. Hassemer (2008, p. 223-224).

${ }^{27}$ Assim, Liszt (2003, p. 139-141).

${ }^{28}$ Nesse sentido, cfr. Roxin (2006, p. 19 e ss.)
} 
Com esses exemplos, vê-se que a noção de bem jurídico não pode ser determinada com a pretensão de se encontrar um conceito fechado capaz de traçar a fronteira entre o que legitimamente pode e não pode ser criminalizado, embora haja um consenso bastante largo sobre a existência de um núcleo essencial ${ }^{29}$.

Desta feita, em maior ou menor grau, o farol que o ilumina aponta, sobremaneira, para o pensamento jurídico racional da ilustração, cuja ideia central é o equilíbrio entre o poder de intervenção estatal e a liberdade civil, trazendo-se para esta composição a constante interação existente entre os interesses do indivíduo e os interesses do corpo social para manutenção da concepção ideológica do contrato social

O que sucede é que nessa renitente simbiose entre a defesa dos interesses do indivíduo e a defesa dos interesses da comunidade, dentro de uma perspectiva positivista, constrói-se um edifício inabalável que impede a assunção crítica de uma visão distinta.

Assim, a ultrapassagem que se sugere para conferir dignidade jurídico-penal aos bens jurídicos deve conduzir à sua definição a partir de uma concepção sociológica, funcionalista, em que o objeto de valor exprima o reconhecimento intersubjetivo e cuja proteção a comunidade considere essencial para realização individual do cidadão participante ${ }^{30}$.

Se a função do direito penal é, conforme acentuado preteritamente, tutelar bens jurídicos essenciais à realização mais livre possível do indivíduo na comunidade - e vice-versa -, então nada obsta que o campo investigativo revele, a partir de um traço evolutivo social, o que é tido como fundamental a este propósito e a esta luz.

\footnotetext{
${ }^{29}$ Sobre alguns critérios que auxiliam na delimitação do conceito de bem jurídico, Cfr. Roxin (2006, p. 20-25). E, para maior aprofundamento acerca das funções atribuídas ao bem jurídico, Cfr. Prado (1996, p. 51-52) e Gomes (2007, p. 386-388).

${ }^{30}$ A teoria filosófica defendida por Habermas (2009) sustenta a ideia de intersubjetividade como fundamento da racionalidade e sua tese promove uma mudança de paradigma, tendo em vista que a intersubjetividade passa ocupar o lugar da subjetividade, desta feita ele desenvolve uma razão interpessoal e não mais simplesmente subjetiva. Esse entendimento da verdade nasce do agir comunicativo, da verdade intersubjetiva, que surge do diálogo dos indivíduos. Na visão de Castilho (2012, p. 266), de forma resumida, o projeto filosófico de Habermas é uma crítica ao positivismo e ao que considera ser uma ideologia resultante do pensamento positivista, que é o tecnicismo, segundo o qual somente a pesquisa técnica e científica promove o desenvolvimento. Segundo ele, a filosofia, para Habermas, não pode ser apenas uma observadora das ciências, mas um instrumento para refinar o pensamento do homem. Esclarece ainda que Habermas somou, a esses posicionamentos filosóficos, o que pode ser considerada a quarta fase da Escola de Frankfurt, a ideia de que a teoria Crítica deve estar engajada nas lutas políticas para obter a transformação do futuro. Assim, Habermas considera que, numa democracia, o cidadão deve ser, ao mesmo tempo, destinatário e autor das normas jurídicas. Por isso, define uma relação de autonomia recíproca entre soberania do povo (pública) e direitos humanos (privados). Soberania popular porque todos os destinatários da norma jurídica devem concordar com ela. E direitos humanos porque a norma jurídica deve abranger a ação orientada pelo interesse privado.
} 
Com esse sentir, reaviva-se a digressão realizada nos tópicos antecedentes acerca do modelo político necessário para atender a sociedade contemporânea, em cuja oportunidade fincaram-se os matizes das dimensões individuais e comunitárias, correspondentes ao liberalismo clássico e ao comunitarismo ${ }^{31}$.

Forçoso, então, delinear que, se por um lado, o liberalismo clássico traz a conquista da individualidade, por outro, não reconhece a comunidade. E, ao revés, o comunitarismo vem justamente trazer o senso de pertencimento a uma comunidade, porém excluindo quem nela não se encaixa.

Nessa zona de divergência - e algumas vezes de imbricação -, entre a dimensão pessoal e a dimensão cultural, é que, preponderantemente, oscilam as construções teóricas sobre o bem jurídico, não faltando exemplos de bens jurídicos emergentes e bens jurídicos evanescentes frutos dessa mutabilidade.

Entrementes, a reflexão aqui proposta vai ao encontro da percepção segundo a qual em um momento histórico de complexificação das sociedades e de crescente atenção à multiculturalidade - a sociedade não se satisfaz apenas com o atendimento da dimensão individual da pessoa e/ou da dimensão cultural da pessoa, sendo fundamental, portanto, incluir entre estas a dimensão cidadã da pessoa ${ }^{32}$.

Assim, solidificam-se as bases de uma ordem pública ${ }^{33}$ na qual o cidadão se encontra no indivíduo e no comunitário e cujo modelo político se exercita através da democracia deliberativa ${ }^{34}$.

\footnotetext{
${ }^{31}$ Sobre a temática, remete-se o leitor à nota explicativa de $\mathrm{n}^{\mathrm{o}} 5$.

${ }^{32}$ Conquanto Habermas não tenha formulado um conceito sobre cidadania, a ideia que a envolve nesta abordagem contempla uma dimensão ativa da pessoa e que lhe proporciona identidade política e uma ação comunicativa na esfera pública de uma democracia deliberativa.

${ }^{33}$ De significativa importância, não olvidar do conceito de ordem pública delimitado na nota explicativa de $\mathrm{n}^{\circ} 2$.

${ }^{34}$ Para Habermas (2009), a democracia deliberativa constitui-se como um modelo ou processo de deliberação política democrática caracterizado por um conjunto de pressupostos teórico-normativos que incorporam a participação da sociedade civil na regulação da vida coletiva. Trata-se de um conceito que contraria o liberalismo e está fundamentalmente ancorado na ideia de que a legitimidade das decisões e ações políticas deriva da deliberação pública da maioria, pelos cidadãos, em geral, livres e iguais. Nesse caminhar, é fundamental levar em conta que, em princípio, o conceito de "deliberação" pode se relacionar a dois tipos de situação: uma primeira, na qual o que está em jogo é, de fato, o poder de decidir (isto é, quando uma decisão se mostra mandatória); uma segunda situação, relativa preferencialmente à disposição dos agentes em discutir, com a finalidade de aprimorar suas perspectivas de mundo (sem, necessariamente, precisar ser tomada uma decisão). Desta forma, com sua base no exercício da razão comunicacional, a democracia deliberativa está fundada na premissa de que cidadãos e representantes políticos se devem justificativas mútuas. E, essa troca de justificativas construiriam soluções mais legítimas, complexas e capazes de viabilizar um esclarecimento recíproco dos cidadãos e a formação da opinião pública. Assim sendo, a troca é vista como a base do debate público e é fundamental para a legitimidade democrática de uma sociedade.
} 
Nesse percurso, é necessário que o adestramento do corpo social através do espaço público desate seu ponto de amarração fincado no liberalismo clássico e/ou no comunitarismo para adquirir liberdade de movimentos através da democracia deliberativa, a fim de que a cidadania seja considerada em sua dimensão ativa ${ }^{35}$ e que proporcione identidade política e uma ação comunicativa ${ }^{36}$ na esfera pública.

Em tal ambiente - no qual a cidadania pode ser exercida de modo pleno, levando ao aprimoramento da democracia - os meios (dialogais sobretudo), utilizados para o alcance da plenitude reivindicada, dirão se é legítimo, ou não, o exercício do controle social institucionalizado na volição do sistema penal ${ }^{37}$, dirão exatamente se o modo como este é aplicado se coaduna com os princípios basilares do Estado Democrático de Direito.

Dessa forma, o pressuposto inafastável contempla o entendimento segundo o qual a garantia de uma elaboração legislativa penal coerente, justa e segura do jus puniendi é a concretude democrática, através de uma composição demográfica racional ${ }^{38}$.

35 Ao encontro dessa liberdade de movimentos que se pretende alcançar através da democracia deliberativa, Guimarães (2010) acrescenta que é imprescindível ultrapassar as fronteiras de uma democracia meramente formal para que se possa entender como procedentes os fundamentos apresentados para legitimar o direito de punir, vez que somente através da concretização de uma democracia plena ou substancial - em que o exercício da cidadania ativa, e a efetiva capacidade de escolha que esta possibilita, evolui e transforma-se em cidadania democrática - é que se alcançará as exigências mínimas de validade do pacto social no âmbito punitivo. Nesse conduto, aclarando a visão sobre cidadania democrática, Dias $(2008$, p. 69) assevera que às formas de agressão produzidas pelos novos riscos que deterioram o reconhecimento recíproco e aumentam a vulnerabilidade humana presente e futura - a cidadania democrática contrapõe a eleição de novos valores humanos, traduzidos e expressos na linguagem dos direitos e dos bens jurídicos, e de novos mecanismos de proteção.

36 A ação comunicativa trata-se de uma análise teórica e epistêmica da racionalidade como sistema operante da sociedade. Através dela Habermas (1989) contrapõe-se à ideia de que a razão instrumental constitua a própria racionalização da sociedade ou o único padrão de racionalização possível, e introduz o conceito de razão comunicativa. Partindo da perspectiva que os seres humanos fazem coisas com as palavras e que a linguagem constitui uma importante ferramenta de transformação, ele argumenta que, através da ação comunicativa, é possível transformar os aspectos objetivos, subjetivos e sociais do mundo. Seu objetivo é propor uma alternativa racional à razão instrumental como fundamento da modernidade a partir de uma ampliação e refinamento da própria ideia de razão. A ação comunicativa geraria razoabilidade, racionalidade e criticidade, representado uma alternativa à ação estratégica, que seria voltada apenas para os interesses de um grupo ou indivíduo específico. Assim sendo, propõe a ação comunicativa como forma de fazer com que todos os envolvidos em uma deliberação passem a buscar o consenso em torno de uma solução que beneficie a todos igualmente. Nessa trilha, ele buscou definir as normas universais da ação comunicativa. Segundo ele, para que o intercâmbio de argumentos, como procedimento para resolução de questões ético-morais, seja realmente efetivo, faz-se necessário uma aproximação da situação ideal de fala, a qual é caracterizada por: a) Imparcialidade; b) Expectativa de que todos os participantes transcendam suas preferências iniciais; c) Inclusão de todos os afetados por uma decisão; d) Igualdade, liberdade e facilidade de interação, com ausência de formas de coerção externas e internas; e) Não restrição de tópicos nas discussões; f) Revisibilidade de resultados.

${ }^{37}$ A referência a esta temática encontra-se abordada pelas notas explicativas de $\mathrm{n}^{\mathrm{o}} 13,14 \mathrm{e} 15$.

${ }^{38}$ Sobre a terminologia “ composição demográfica racional”, Guimarães (2010, p. 36 e ss.) a utiliza na acepção da capacidade intelectiva dos indivíduos fazerem suas escolhas, o que leva ao exercício de uma cidadania ativa, com influência direta nos rumos da democracia representativa, ou seja, todos os problemas ligados à política, somente serão solucionados no próprio âmbito desta, é dizer: precisa-se avançar na órbita de implementação de uma democracia substancial, na qual, em um contexto ideal, todos os membros do corpo social possam fazer escolhas 
Diante disso, a postura a ser adotada enreda o fato de que o conceito sociológico de bem jurídico $^{39}$ deve ser delineado com o objetivo de materializá-lo a partir da perspectiva de um consenso racional $^{40}$ intersubjetivo - uma identidade social - fundada na capacidade de fazer escolhas e na possibilidade de exercer o controle da implementação adequada, ou não, das escolhas efetivadas ${ }^{41}$.

Em síntese, para que sejam preservadas as condições fundamentais da mais livre realização possível da personalidade de cada homem no seio do corpo social, é mister que a árdua tarefa de enquadramento conceitual do bem jurídico, além de ser sufragada naquilo que caracteriza a identidade jurídica de cada sociedade, deve encontrar-se refletido em um valor jurídico-constitucionalmente reconhecido e que preexista ao ordenamento jurídico penal de forma que a cidadania ativa jamais se sobreponha ao valor jurídico constitucional. Ao revés, componha com ele a ordem pública necessária para o exercício de direitos fundados na democracia deliberativa.

\section{CONCLUSÃO.}

Diuturnamente o sistema penal frustra as expectativas criadas pelo corpo social, cujo afã resolutivo intenta debelar problemas políticos e sociais não equacionados por outras esferas

\footnotetext{
responsáveis, de maneira racional. Imprescindível que os componentes da sociedade aprendam a controlar o poder que disponibilizam para seus representantes legais.

${ }^{39}$ A definição de bem jurídico desenvolvida por Kindhäuser (2017, p. 65-92), à luz da autonomia comunicativa, entende serem os bens jurídicos como qualidades das pessoas, coisas ou instituições, as quais facilitam ou asseguram a participação livre e igualitária em um acordo normativo. De forma que, se o Direito Penal tem por fim o asseguramento dos fundamentos jurídicos de uma sociedade, os bens jurídicos por ele protegidos são os que representam tanto a identidade jurídica de uma sociedade de estrutura concreta, como também, os pressupostos para sua constante reprodução.

${ }^{40}$ Para Habermas $(2009$, p. 254 e ss.) a correta justificação racional das normas, dentro de uma teoria do discurso, deve, necessariamente, passar por duas fases de avaliação. A primeira fase, refere-se à averiguação do respeito às condições ideais de discurso: a) necessidade de que os proferimentos sejam gerais e produzam entendimento idêntico entre os falantes; b) publicidade e inclusão geral, participação com direitos iguais, respeito e reconhecimento mútuo, responsabilidade por parte dos falantes, sinceridade (vontade dos falantes em se entender) e autonomia (imunização contra coerções externas e internas). A segunda, às condições do discurso prático, ou seja, se se evidenciam a adequação, necessidade e proporcionalidade da norma.

${ }^{41}$ Sobre o assunto, Kindhäuser (2006, p. 48-52) assevera que, no âmbito do Direito, o importante é que haja um consenso de resultado, ou seja, que os atores sociais, através do processo de ação comunicativa - que é permeado pela autonomia e lealdade comunicativas - alcancem a integração social, que é o processo de reconhecimento do outro como pessoa para alcance do acordo quanto ao conteúdo normativo e, assim, cheguem a um compromisso para cumprimento das normas. Demais disso, adverte que, por meio de mandados básicos de legitimidade constitucional que garantam a proteção dos direitos de personalidade e protejam as minorias, é possível fazer o controle democrático de elaboração legislativa, garantindo, assim, de forma jurídica, o impedimento de criação de uma legislação pautada em flutuações políticas de opinião e de ocasião. Assim, vaticina, é a democracia sob o domínio do Direito.
} 
de controle social ou mesmo ante a própria ausência de políticas destinadas a garantir prestações públicas essenciais à população.

Por essa razão, o Direito Penal é elevado à categoria de trincheira de batalha multidirecional apontada tanto a aspectos intrassitemáticos, quanto a aspectos extrassistemáticos, olvidando-se, contudo, que o Direito Penal ocupa somente um lugar limitado dentro deste sistema, sendo indispensável manter a racionalidade acerca do dimensionamento de seu campo de controle.

Nesse caminhar, a complexidade de encontrar uma solução para o expendido acresce em dificuldade quando se tem em consideração as características da sociedade contemporânea e os desencadeamentos que as condutas realizadas pelo corpo social produzem, redundando, amiúde, em um cabo de guerra entre a liberdade e a segurança.

E, dentro desse campo de embate, o lineamento percorrido buscou, primeiramente, equacionar a tarefa prática de aplicação do Direito Penal em um espaço de ordem pública cujo corpo social não tem consciência do protagonismo que deve exercer.

Partiu-se do liberalismo clássico, ultrapassando-se o comunitarismo para fincar atenção na democracia deliberativa, a fim de que a conceituação de bem jurídico afaste-se da pretensão de se encontrar um conceito fechado, apriorístico.

Nesse esforço, apresentou-se a perspectiva positivista de bem jurídico em prol da assunção crítica de uma visão distinta, a qual encontra campo para desenvolver-se através da sociologia do bem jurídico.

Feita essa ultrapassagem, a dignidade jurídico-penal dos bens jurídicos passa a ser definida por intermédio de um objeto de valor que exprime o reconhecimento intersubjetivo dos cidadãos e cuja proteção a comunidade considere essencial para realização individual de cada um pertencente ao corpo social, conferindo-se, por esse caminho, juridicidade às escolhas do legislador.

Alinhavadas essas premissas, o corpo social passa a adquirir liberdade de movimentos, através da democracia deliberativa e do exercício da cidadania considerada em sua dimensão ativa, capaz de proporcionar identidade política e uma ação comunicativa na esfera pública.

E, nesse ambiente em que a democracia se aprimora, amplia-se o diálogo entre os integrantes do corpo social no intuito de aferir se é legítimo, ou não, o exercício do controle 
social institucionalizado na volição do sistema penal, pela integração entre os desejos da sociedade, a vontade do legislador e as exigências constitucionais afetas à matéria.

Alfim, conclui-se sobrelevando que, para a preservação das condições fundamentais da mais livre realização possível da personalidade de cada homem no seio do corpo social, é mister que a árdua tarefa de enquadramento conceitual do bem jurídico, além de ser sufragada naquilo que caracteriza a identidade jurídica de cada sociedade, deve encontrar-se refletida em um valor jurídico-constitucionalmente reconhecido e que preexista ao ordenamento jurídico penal, de forma que a cidadania ativa jamais se sobreponha ao valor jurídico constitucional. Ao revés, componha com ele a ordem pública necessária para o exercício de direitos fundados na democracia deliberativa.

\section{REFERÊNCIAS BIBLIOGRÁFICAS}

ASHWORTH, Andrew. Principles of Criminal Law. 6 ed. London: Oxford University Press, 2009.

ALVES, Silvia. Punir e humanizar. O Direito Penal setecentista. 2008. 1555f. Tese (Doutorado em Direito) - Faculdade de Direito da Universidade de Lisboa, vol. I, Lisboa, 2008.

BACHELARD, Gaston. A formação do espírito científico: contribuição para uma análise do conhecimento. Tradução de Estela dos Santos Abreu. Rio de Janeiro: Contraponto, 1999.

BATISTA, Nilo. Mídia e Sistema Penal no Capitalismo Tardio. Discursos Sediciosos. Crime, Direito e Sociedade. Rio de Janeiro, ano 7, n. 12. p. 271, 2 . Semestre de 2002.

BAUMAN, Zygmunt. Modernidade Líquida. Rio de Janeiro: Jorge Zahar, 2001.

BECK, Ulrich. La sociedade del riesgo. Barcelona: Civitas, 1998.

BUERGO, Blanca Mendoza. El Derecho Penal en la Sociedad del Riesgo. Madrid: Civitas, 2001.

CANOtilho, J. J. Gomes. Direito Constitucional e Teoria da Constituição. 4. ed. Coimbra: Almedina, 2003.

CARVAlHO, Márcia Dometila Lima de. Fundamentação Constitucional do Direito Penal. Porto Alegre: SAFE, 1992.

CASTILHO, Ricardo. Filosofia do Direito. São Paulo: Saraiva, 2012.

CAVAlCANTI, Eduardo Medeiros. Crime e Sociedade Complexa: uma abordagem interdisciplinar sobre o processo de criminalização. Campinas - SP: LNZ, 2005.

CLEMENTE, Pedro José Lopes. Cidadania, Polícia e Segurança. Lisboa: ISCPSI, 2015.

CUNHA, Paulo Ferreira da. A Constituição do crime: da substancial constitucionalidade do Direito Penal. Coimbra: Coimbra, 1998.

DIAS, Jorge Figueiredo. O Direito Penal entre a "sociedade industrial" e a "sociedade do risco". Revista Brasileira de Ciência Criminais. São Paulo: RT, ano 9, nº 33, 2001.

. Direito penal: parte geral. Tomo I. Questões fundamentais: a doutrina geral do crime. São Paulo: Revista dos Tribunais, 2007. 
DIAS, Augusto Silva. Ramos emergentes do Direito Penal relacionados com a proteção do futuro. Coimbra: Coimbra Editora, 2008.

DORNELLES, João Ricardo. Ofensiva neoliberal, globalização da violência e controle social. Discursos Sediciosos. Crime, Direito e Sociedade. Rio de Janeiro, ano 7, n. 12. p. 123, $2^{\circ}$. Semestre de 2002.

DURKHEIM, Émile. Selected Writings. Cambridge: Cambridge University Press, 1972.

FERNANDES, Paulo Silva. Globalização, "Sociedade de Risco" e o Futuro do Direito Penal. Coimbra: Almedina, 2001.

FOUCAULT, Michel. A verdade e as formas jurídicas. $3^{\text {a }}$ ed. Rio de Janeiro: Nau, 2003.

FREIRE JÚNIOR. Américo Bedê; Senna, Gustavo. Princípios do Processo Penal: entre o garantismo e a efetividade da sanção. São Paulo: RT, 2009.

GARLAND, David. Castigo y sociedad moderna. Un estudio de Teoria Social. Madrid: Siglo Veintiuno, 1999.

As contradições da Sociedade Punitiva: o caso britânico. Discursos

Sediciosos. Crime, Direito e Sociedade. Rio de Janeiro, ano 7, n. 12. p. 86, $2^{\circ}$. Semestre de 2002.

GAROFALO, Rafael. Criminologia. Tradução de Danielle Maria Gonzaga. Campinas: PED, 1997.

GOMES, Luiz Flávio. Direito Penal. volume 1. Introdução e princípios fundamentais. São Paulo: Revista dos Tribunais, 2007.

GUIMARÃES, Claudio Alberto Gabriel. Bem jurídico penal. Juris Itinera. Revista do Ministério Público do Estado do Maranhão. São Luis, 2000.

capitalista. 2 ed., Rio de Janeiro: Revan, 2007.

Funções da pena privativa de liberdade no sistema penal Constituição, Ministério Público e Direito Penal. A defesa do Estado

Democrático no âmbito punitivo. Rio de Janeiro: Revan, 2010.

. Reflexões acerca do controle social formal: rediscutindo os fundamentos

do direito de punir. Revista da Faculdade de Direito da UERJ-RFD. Rio de Janeiro, v. 1, n. 23, 2013. Disponível em: http://www.e-publicacoes.uerj.br/index.php/rfduerj/article/view/4894 Acesso em 02 de fevereiro de 2019.

Teorias críticas e Direito Criminal: sobre os fundamentos e a legitimação do direito de punir. Rio de Janeiro: REVAN, 2018.

GUSTIN, Miracy Barbosa de Sousa. DIAS, Maria Tereza Fonseca. (Re) pensando a pesquisa jurídica: teoria e prática. Belo Horizonte: Del Rey, 2015.

HABERMAS, Jürgen. Consciência Moral e Agir Comunicativo. Rio de Janeiro: Tempo Brasileiro, 1989

Verdade e justificação: ensaios filosóficos. São Paulo: Loyola, 2009.

Hart, Herbert L. A. Prolegomenon to the Principles of Punishment. In: HART, Herbert L. A. Punishment and Responsibility. Oxford: Clarendon Press, 1968.

HASSEMER, Winfried. Direito Penal: fundamentos, estrutura, política. Porto Alegre: Sergio Antonio Fabris, 2008.

HEGEL, Georg W. F. Princípios da filosofia do direito. Tradução de Norberto de Paula Lima. São Paulo: Ícone, 1997.

HIRSCH, Andrew Von. Paternalismo direto: autolesões devem ser punidas penalmente? Revista Brasileira de Ciências Criminais, n. 67, jul./agos. de 2007, p. 11-28.

KINDHÄUSER, Urs. Derecho Penal de la culpabilidad y conducta peligrosa. Bogotá: Universidad Externado de Colombia, 2006. 
Bien Jurídico, Seguridad e hecho punible desde una perspectiva comunicativa del Derecho Penal. San Justo: Universidad Nacional de La Matanza, 2017.

KIST, Dário José. Bem jurídico-penal: evolução histórica, conceituação e funções. Direito e Democracia. Canoas, v. 4, n. 1, p. 145-179, 1'. Semestre de 2003.

LISZT, Franz Von. Tratado de Direito Penal Alemão. Campinas: Russel, 2003.

LUISI, Luiz. Os Princípios Constitucionais Penais. Porto Alegre: Sergio Antonio Fabris Editor, 1991.

MAÑALICH, Juan Pablo. La pena como retribuçión. Revista de Estudios Públicos, n. 108, 2007, p. 117-205.

MARQUES, José Frederico. Tratado de Direito Penal. Campinas-SP: Bookseller, vol. II, 1997. MERTON, Robert K. Teoria social y estructura sociales. Trad. Florentino M. Torner. México: Fondo de Cultura, 1964.

MINAYO, Maria Cecília de Souza. (ORG.). Pesquisa Social. Teoria, método e criatividade. Petrópolis: Vozes, 2018.

MUÑ̃Z CONDE, Francisco. Derecho penal y control social. Bogotá: Editorial Temis, 2012.

OLIVEIRA, Tarsis Barreto. Pena e racionalidade. Rio de Janeiro: Lumen Juris, 2017.

PALMA, Maria Fernanda. Direito Constitucional Penal. Lisboa: Almedina, 2006.

jul./dez. de 2014, p. 11-26.

Conceito material de crime e reforma penal. Anatomia do crime, n. 0 ,

- O argumento criminológico e o princípio da necessidade da pena no juízo de constitucionalidade. Julgar, n. 29, 2016, p. 105-121.

. Direito Penal. Conceito material da crime, princípios e fundamentos.

Teoria da lei penal: interpretação, aplicação no tempo, no espaço e quanto às pessoas. Lisboa: AAFDL Editora, 2018.

PIRES, Álvaro. A racionalidade penal moderna, o público e os direitos humanos. Novos Estudos, n. 68, março de 2004. Disponível em: https://edisciplinas.usp.br/pluginfile.php/121354/mod_resource/content/1/Pires_A\%20racionalid ade\%20penal\%20moderna.pdf acesso em 22 de jan. de 2019

PRADO, Luiz Regis. Bem jurídico penal e constituição. São Paulo: Revista dos Tribunais, 1996.

RAWLS, John. O Liberalismo político. São Paulo: Ática, 2000.

ROBINSON, Paul. H. El principio de proporcionalidad y merecimiento empírico. Revista de Estudios de la Justicia, n. 22, 2015.

ROUSSEAU, Jean-Jacques. Do contrato social. São Paulo: Martin Claret, 2013.

ROXIN, Claus. Sentido y Límites de la Pena Estatal. In: ROXIN, Claus. Problemas Básicos del Derecho Penal. Madrid: Reus, 1976.

de Janeiro: Renovar, 2000a.

Política criminal e sistema jurídico-penal. Tradução de Luís Greco. Rio

La evolución de la Política Criminal, el Derecho penal y el Proceso penal. Valência: Tirant Lo Blanch, 2000b.

. A proteção de bens jurídicos como função do direito penal. Porto Alegre: Livraria do Advogado, 2006.

SANDEL, Michael. Democracy's Discontent: America in Search of a Public Philosophy, Cambridge, Massachusetts: Harvard University Press, 1996.

SIEYÈS, Emmanuel Joseph. Qu'est-ce que le tier état? PUF, 1982.

SILVA, Pablo Rodrigo Aflen da. Leis Penais em Branco e o Direito Penal do Risco: aspectos críticos e fundamentais. Rio de Janeiro: Lumen Juris, 2004. 
STRECK, Lenio Luiz; FELDENS, Luciano. Crime e Constituição: a legitimidade da função investigatória do Ministério Público. Rio de Janeiro: Forense, 2003.

THOREAU, Henry David. A desobediência civil seguido de Walden. Porto Alegre: L\&PM, 2017.

TOLEDO, Francisco de Assis. Princípios Básicos de Direito Penal. São Paulo: Saraiva, 1994 VIANA, Túlio Lima. A era do controle: introdução crítica ao direito penal cibernético. Discursos Sediciosos. Crime, Direito e Sociedade. Rio de Janeiro, ano 9, n. 14. p. 63, $1^{\circ}$ e $2^{\circ}$. Semestre de 2002.

WALZER, Michael. Esferas da Justiça: uma defesa do pluralismo e da igualdade. São Paulo: Martins Fontes, 2003.

WELZEL, Hans. Derecho Penal. Parte General. Trad. Carlos Fontán Balestra. Depalma: Buenos Aires, 1956.

ZAFFARONI, Eugenio Raúl; PIERANGELI, José Henrique. Manual de Direito Penal Brasileiro: parte geral. 2 ed. São Paulo: RT, 1999. 